Article

\title{
The Plasma Spectroscopic Study of Dergaon Meteorite, India
}

\author{
Abhishek K. Rai ${ }^{1}$, Jayanta K. Pati ${ }^{1,2}$, Christian G. Parigger ${ }^{3, *(D)}$, Sonali Dubey ${ }^{4}$, \\ Awadhesh K. Rai ${ }^{4}$, Balen Bhagabaty ${ }^{5}$, Amulya C. Mazumdar ${ }^{5}$ and Kalpana Duorah ${ }^{6}$ \\ 1 Department of Earth and Planetary Sciences, Nehru Science Centre, University of Allahabad, Allahabad \\ 211002, India; abhishekraigeology@gmail.com (A.K.R.); jkpati@gmail.com (J.K.P.) \\ 2 National Center of Experimental Mineralogy and Petrology, 14, Chatham Lines, University of Allahabad, \\ Allahabad 211002, India \\ 3 Department of Physics and Astronomy, University of Tennessee/University of Tennessee Space Institute,411 \\ B. H. Goethert Parkway, Tullahoma, TN 37388, USA \\ 4 Department of Physics, University of Allahabad, Allahabad 211002, India; \\ sonalidubey193.sd@gmail.com (S.D.); awadheshkrai@gmail.com (A.K.R.) \\ 5 Department of Geological Sciences, Gauhati University, Guwahati 781014, India; \\ b_bhagabaty@gauhati.ac.in (B.B.); acmazumdar@gauhati.ac.in (A.C.M.) \\ 6 Department of Physics, Gauhati University, Guwahati 781014, India; hl_duorah@yahoo.com or \\ khowang56@yahoo.com \\ * Correspondence: cparigge@tennessee.edu; Tel.: +1-931-841-5690
}

Academic Editor: Andrzej Grzechnik

Received: 26 January 2020; Accepted: 19 February 2020; Published: 22 February 2020

\begin{abstract}
Meteorites are the recoverable portions of asteroids that reach the surface of the Earth. Meteorites are rare extraterrestrial objects studied extensively to improve our understanding of planetary evolution. In this work, we used calibration-free laser-induced breakdown spectroscopy (CF-LIBS) to evaluate the quantitative elemental and molecular analyses of the Dergaon meteorite, a $\mathrm{H}$ 4-5 chondrite fall sample from Assam, India. Spectral signatures of $\mathrm{H}, \mathrm{N}, \mathrm{O}, \mathrm{Na}, \mathrm{Mg}, \mathrm{Al}, \mathrm{Si}$, $\mathrm{P}, \mathrm{K}, \mathrm{Ca}, \mathrm{Ti}, \mathrm{Cr}, \mathrm{Mn}, \mathrm{Fe}, \mathrm{Co}, \mathrm{Ni}$, andIrweredetected. Along with the atomic emission, this work reports the molecular emission from FeO molecules. The concentration of the measured elements obtained using CF-LIBS is in close agreement with earlier reports. The elements $\mathrm{H}, \mathrm{N}$, and $\mathrm{O}$ and their concentrations are estimated by using CF-LIBS for the first time. This study applies laser spectroscopy to establish the presence of $\mathrm{Ni}, \mathrm{Cr}, \mathrm{Co}$, and $\mathrm{Ir}$ in meteorites. The elemental analysis forms the basis for the establishment of the potential molecular composition of the Dergaon meteorite. Moreover, the elemental analysis approach bodes well for in-situ analyses of extraterrestrial objects including applications in planetary rover missions.
\end{abstract}

Keywords: Dergaon meteorite; calibration-free laser-induced breakdown spectroscopy; atomic spectroscopy; molecular spectroscopy; planetary geochemistry

\section{Introduction}

Meteorites are the recoverable portions of asteroids that reach the surface of the Earth. The meteorites that are observed to fall and are collected are classified as "falls". The remaining extraterrestrial objects of unknown age are grouped under "finds". Only less than 2\% of all meteorites (iron, stony, and stony-irons) collected to date are classified as "falls." The Dergaon meteorite is one such "fall", observed on March 2, 2001, at 16:40 hrs (Meteoritical Bulletin, 2001) near Dergaon (96 46"48"; $\left.26^{\circ} 46^{\prime} 32^{\prime \prime}\right)$ village in Assam State, India. It is an ordinary chondrite (H 4-5) representing shock stage S5 [1] and comprises about ten different types of chondrules [2,3] with a variable chondrule: matrix ratio (60:40-80:20) [3]. The minerals that are present include:olivine (Ol: $\left.\sim \mathrm{Fo}_{80}-\mathrm{Fa}_{20}\right)$, orthopyroxene 
$\left(\mathrm{Opx}: \sim \mathrm{En}_{82}-\mathrm{Fs}_{18}\right)$, clinopyroxene $\left(\mathrm{Cpx}: \sim \mathrm{Wo}_{47}-\mathrm{En}_{46}-\mathrm{Fs}_{7}\right)$, plagioclase (Plag: $\left.\mathrm{Ab}_{87}-\mathrm{An}_{13}\right)$, chlorapatite, chromite, merrillite, kamacite-taenite, and troilite [3]. In addition to about $92 \%$ of the volume of mineral phases, glass constitutes about $8 \%$ of the total volume [3]. It is a relatively well studied chondritic meteorite [3-10] possessing some interesting characteristics, such as potassium-depletion associated with vesiculated feldspars and the presence of aliphatic hydrocarbons [8,9] and nano-diamonds [10], observed using conventional analytical techniques including Gamma Ray, FTIR, and Laser Raman. The meteorite was successfully analyzed by laser-induced breakdown spectroscopy (LIBS) [11-16]. The calibration-free LIBS (CF-LIBS) approach was used to determine the elemental composition of the Dergaon meteorite. The CF-LIBS method is used for analyzing samples such as soils and rocks [17]. Furthermore, CF-LIBS can also analyze meteorite samples that are not easy to treat by traditional analytical techniques.

Using this approach, the traditional calibration curve is not required to quantify the elements present in the sample. The results obtained from CF-LIBS are compared with the results obtained from Instrumental Neutron Activation Analysis (INAA), Atomic Absorption Spectroscopy (AAS) and Inductively Coupled Plasma-Atomic Emission Spectroscopy (ICP-AES) data [2], and X-ray fluorescence (XRF) data [9] from past literature. Thus, our experiment demonstrates that CF-LIBS is a rapid technique for quantitative analysis, showing the presence of heavy and light elements rapidly while conserving the valuable extraterrestrial sample for posterity. The siderophile element ratio, such as Ni/Cr, with or without the presence of the platinum group of elements (PGE), e.g., Ir, has been used to decipher the presence of extraterrestrial components(such as chondrite meteorites) [18-22]. An attempt is also made in this study to establish the extraterrestrial affinity of the Dergaon sample by using high nickel/chromium content and the presence of iridium (Ir) [21], using LIBS spectral signatures [22]. We have quantified the presence of characteristic elements in the above meteorite using the CF-LIBS technique.

\section{Results and Discussion}

The spectra of Dergaon chondrite were recorded in the range of 200 to $900 \mathrm{~nm}$. Table 1 lists spectral lines for various elements that were identified using the NIST spectral database [23].

Table 1. Spectral lines observed with laser spectroscopy of Dergaon meteorite.

\begin{tabular}{|c|c|}
\hline Species & Major Lines (nm) Present in Dergaon Meteorite \\
\hline $\mathrm{H}(1)$ & 656.3(I) \\
\hline $\mathrm{N}(7)$ & 744.2(I), 746.8(I), 868.3(I) \\
\hline $\mathrm{O}(8)$ & 777.4(I), 844.6(I), 926.6(I) \\
\hline $\mathrm{Na}(11)$ & $588.9(\mathrm{I}), 589.5(\mathrm{I})$ \\
\hline $\mathrm{Mg}(12)$ & 279.0(II), 279.5(II), 280.2(II),285.2(I), 382.9(I), 383.2(I), 383.8(I), 448.1(II), 516.7(I), 517.2(I), 518.3(I) \\
\hline $\mathrm{Al}(13)$ & 308.2(I), 309.2(I), 394.3(I), 396.1(I) \\
\hline $\mathrm{Si}(14)$ & $\begin{array}{c}\text { 220.7(I), 221.0(I), 221.6(I), 250.6(I), 251.4(I), 251.6(I), 251.9(I), 252.8(I), 288.1(I), 390.5(I), } \\
413.1(\mathrm{II}), 557.6(\mathrm{II}), 634.7(\mathrm{II})\end{array}$ \\
\hline $\mathrm{P}(15)$ & 645.9(II), 650.3(II), 650.7(II) \\
\hline K (19) & $766.4(\mathrm{I}), 769.8(\mathrm{I})$ \\
\hline $\mathrm{Ca}(20)$ & $\begin{array}{c}\text { 315.8(II), 317.9(II), 370.6(II), 373.6(II), 393.2(II), 396.7(II), 370.5(II), 422.6(I), 430.2(I), 442.5(I), 443.9(I), } \\
\text { 445.4(I), 501.9(II), 518.8(I), 558.7(I), 610.2(I), 612.2(I), 616.2(I), 645.6(II), 646.2(I), 649.5(I), 647.2(I), } \\
\text { 720.1(I) }\end{array}$ \\
\hline $\mathrm{Ti}(22)$ & 334.9(II), 336.1(II) \\
\hline $\mathrm{Cr}(24)$ & 283.5(II), 284.3(II), 284.9.(II), 302.0(I), 359.3(I), 360.5(I), 369.5(I), 381.5(I), 385.5(I), 428.9(I) \\
\hline Mn (25) & 257.6(II), 279.4(I), 279.8(I), 280.1(I), 380.6(I), 403.0(I), 403.3(I), 403.4(I) \\
\hline $\mathrm{Fe}(26)$ & $\begin{array}{l}\text { 234.3(II), 238.2(II), 239.5(II), 240.4(II), 249.3(II), 250.7(II), 252.4(I), 254.3(II), 256.7(II), } \\
\text { 258.5(II), 259.8(II), 259.9(II), 260.7(II), 261.1(II), 273.9(II), 274.9(II), 275.5(II), 293.6(I), } \\
\text { 305.7(I), 305.9(I), 344.0(I), 358.0(I), 358.1(I), 364.7(I), 371.9(I), 373.4(I), 373.7(I), } \\
\text { 374.5(I), 374.9(I), 375.8(I), 382.0(I), 385.9(I), 404.1(I), 404.5(I), 406.3(I), 432.5(I), 438.3 (I) }\end{array}$ \\
\hline Co (27) & 340.5(I), 344.3(I), 347.3(I), 349.5 (I) \\
\hline $\mathrm{Ni}(28)$ & 338.0(I), 341.3(I), 342.3(I), 349.2(I),352.4(I) \\
\hline $\operatorname{Ir}(77)$ & $351.3(\mathrm{I})$ \\
\hline
\end{tabular}


The spectral lines of the elements present in the LIBS spectra of the Dergaon meteorite are shown in Figure 1a-d. The distinct advantage of LIBS lies in its unique ability to detect heavy as well as light elements, as indicated in Figure 1.

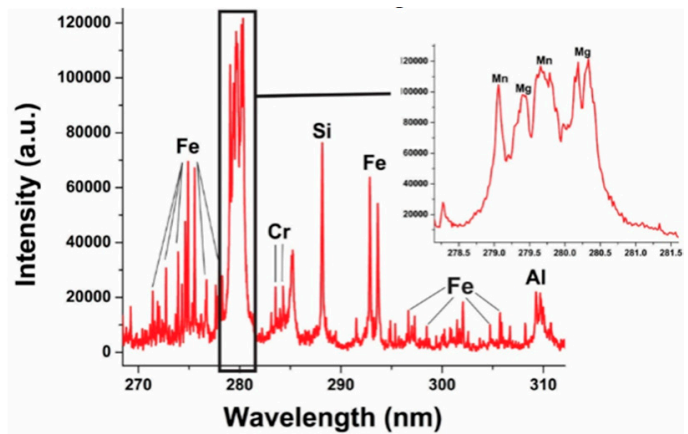

(a)

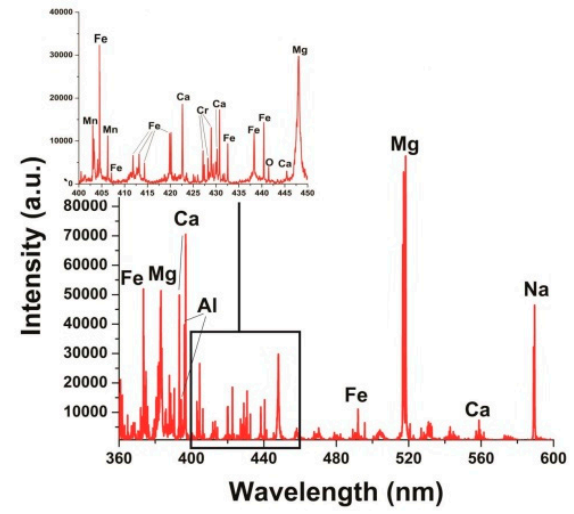

(c)

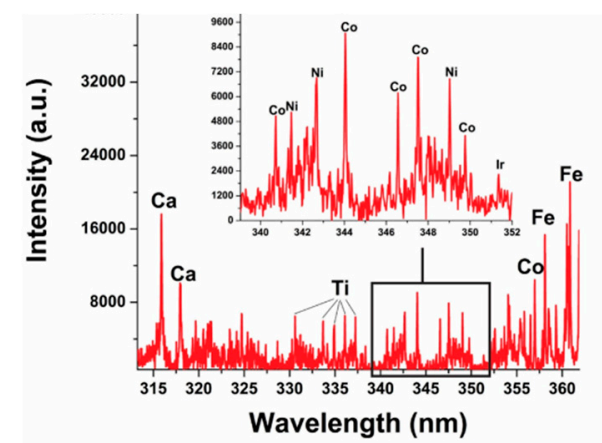

(b)

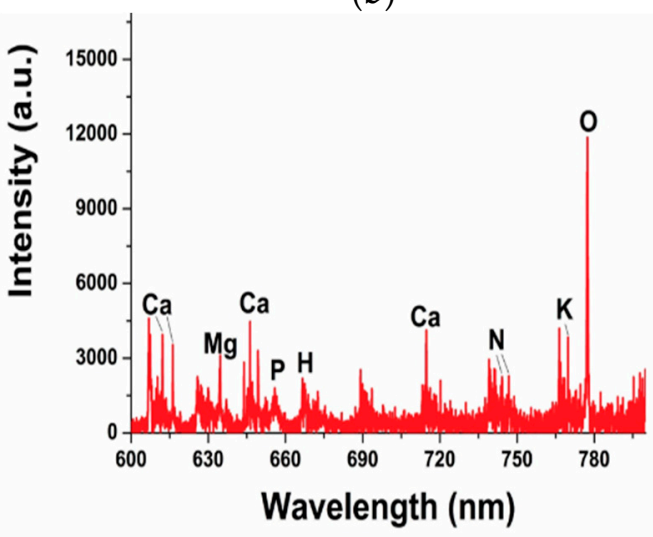

(d)

Figure 1. Typical laser-induced breakdown spectroscopy (LIBS) spectra of Dergaon meteorite in the wavelength range (a) $270-310 \mathrm{~nm}$; (b) 315-360 nm; (c) 360-560 nm; (d) 600-800 nm.

The spectral lines of characteristic trace elements observed in the LIBS spectra of the Dergaon chondritic meteorite include $\mathrm{Cr}, \mathrm{Co}, \mathrm{Ni}$, and $\mathrm{Ir}$, as shown in Figure $1 \mathrm{~b}$. It is essential to mention that $\mathrm{Cr}, \mathrm{Co}$, and $\mathrm{Ni}$ are also found in mafic-ultramafic terrestrial rocks. But iridium (Ir), a platinum group element, very rarely occurs in ultramafic rocks on Earth and is used to trace extraterrestrial signatures [21]. However, the extraterrestrial samples, like chondritic meteorites, show Ni/Cr $>1$ and may contain substantial Ir. Furthermore, the wavelengths of spectral lines for characteristic elements found in the Dergaon meteorite included Ni I (338.05, 341.34, 342.37, 349.29 and 352.454 nm), Co I $(340.51,344.364,347.39$ and $349.56 \mathrm{~nm})$, and Ir I (351.364 nm). Identical spectral lines of these elements are also observed in meteorites, recently analyzed with LIBS [16]. An earlier study of the Dergaon meteorite reported the presence of noble gases and some light elements as well [2]. At a suitable gate delay, the signature of molecular emissions is also expected to occurwith LIBS Our experimental results reveal that the concentration of $\mathrm{Fe}$ and $\mathrm{O}$ in the present sample arean appreciable amounts, i.e., $\cong 28 \%$ and $\cong 34 \%$, respectively. The high concentration of these elements may result in the formation of molecular bands in the recorded spectra [24,25]. Thus, we have tried to identify the molecular band of $\mathrm{FeO}$ in the LIBS spectra of theDergaon meteorite. Figure 2 displays signatures of molecular bands observed in the range of 558 to $564 \mathrm{~nm}$. The molecular spectra belongs to the orange band system of the FeO molecule [26].

For verification, the concentration ratio of $\mathrm{Ni}$ to $\mathrm{Cr}$ (i.e., $\mathrm{Ni} / \mathrm{Cr}>1$ ) was further investigated using a quantitative analysis of elemental constituents present in the Dergaon meteorite [18-22]. In the 
CF-LIBS approach, the intensity of the spectral lines of all the elements present in the material is used and its application involves three assumptions:

(i) optically thin plasma,

(ii) stoichiometric ablation, and

(iii) thermal equilibrium.

The three assumptions (i) to (iii) are discussed in the subsequent paragraphs.

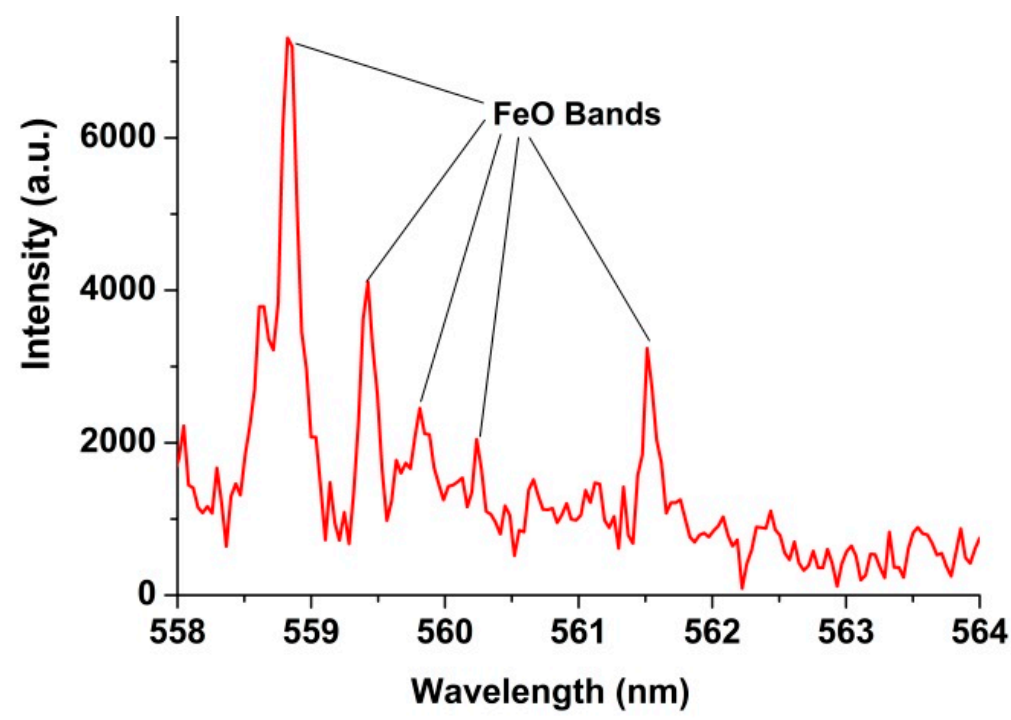

Figure 2. FeO molecular bands recorded with LIBS of the Dergaon meteorite.

\subsection{Optically Thin Plasma}

In CF-LIBS, the measurement of the absolute intensity of spectral lines is required, i.e., the area under the spectral lines profile needs to be determined. The spectral lines used for the measurement of intensity should be free from self-absorption. Thisself-absorption of the spectral line causes distortion of the line profilewhichusually causes errors in the determined area. These errors may lead to the wrong values of electron density and temperature. Therefore, the laser-induced plasma should be optically thin to avoid self-absorption. The plasma is optically thin if the intensity ratio of two interference-free spectral lines of the element that havenearly the same upper energy level is equal to the productof transition probability, statistical weight, and the inverse of the wavelength of these spectral lines. The intensity ratios I/I' for the spectral lines of different species that arepresent in the recorded spectra of the Dergaon meteorite were calculated. We found that these ratios are close to $A_{k i} g_{k} \lambda^{\prime} / A_{k i}^{\prime} g_{k}^{\prime} \lambda$. The results are summarized in Table 2. Consequently, the selected lines for analysis of the laser-induced plasma were optically thin $[27,28]$.

Table 2. Physical parameters required for the calculation of intensity ratios of the two atomic lines for different elements in the recorded spectra of the Dergaon sample.

\begin{tabular}{ccc}
\hline Species & $\mathbf{A}_{\mathbf{k i}} \mathbf{g}_{\mathbf{k}} \boldsymbol{\lambda}^{\prime} / \mathbf{A}_{\mathbf{k i}}^{\prime} \mathbf{g}_{\mathbf{k}}^{\prime} \boldsymbol{\lambda}$ (Theoretical) & $\begin{array}{c}\text { Intensity Ratio, } \mathbf{I} / \mathbf{I}^{\prime} \\
\text { (Experimental) }\end{array}$ \\
\hline Fe-I (374.9/375.8) & 1.59 & $1.43 \pm 0.02$ \\
Ca-II (315.8/317.9) & 0.57 & $0.55 \pm 0.01$ \\
Ca-11 (393.3/375.8) & 2.06 & $1.99 \pm 0.04$ \\
Mg-II (279.5/280.2) & 2.05 & $2.09 \pm 0.05$ \\
Cr-I (359.3/360.5) & 1.30 & $1.22 \pm 0.07$ \\
\hline
\end{tabular}




\subsection{Stoichiometric Ablation}

The intensity of the spectral line present in the laser-induced plasma was directly related to the concentration of the element present in the sample. This was true when the composition of the laser-induced plasma was representative of the target material, i.e., ablation is stoichiometric. It is already experimentally established [28] that when laser irradiance at the focal spot of the sample surface is higher than $10^{9} \mathrm{Wcm}^{-2}$, nearly every nanogram material from the focused spot explodes before the surface layer can vaporize. Therefore, the rapidly heated exploded material in the plasma has the same composition as the target, which leads to stoichiometric ablation [29]. In the present experiments, the laser energy was $15 \mathrm{~mJ}$ and the diameter of the focal spot was about $\approx 12 \mu \mathrm{m}$, and calculated irradiance at the focal spot was found to be $\approx 3.7 \times 10^{12} \mathrm{Wcm}^{-2}$, whichcorresponds to the condition of stoichiometric ablation and suggests that the laser-induced plasma is stoichiometric as laser irradiance is greater than $10^{9} \mathrm{Wcm}^{-2}$.

\subsection{Local Thermodynamic Equilibrium (LTE)}

The intensity of a spectral line, $I_{\lambda}^{k i}$, corresponding to the transition from the upper level ' $\mathrm{k}$ ' to the lower level ' $i$ ', can be calculated using

$$
I_{\lambda}^{k i}=F C_{s} A_{k i} \frac{g_{k} \exp \left\{-\frac{E_{k}}{k_{B} T}\right\}}{Q},
$$

Here, $A_{k i}$ is the transition probability in $\mathrm{sec}^{-1}, \mathrm{~g}_{\mathrm{k}}$ is the degeneracy factor (dimensionless), $\mathrm{C}_{\mathrm{s}}$ is the concentration of the emitting atomic species, $Q$ is the partition function of that species at plasma temperature, $\mathrm{k}_{\mathrm{B}}$ is the Boltzmann constant, $\mathrm{E}_{\mathrm{k}}$ is the energy of the upper level, $\lambda$ is the wavelength of the spectral line, and $\mathrm{F}$ is an experimental parameter which takes into account the optical efficiency of the collection system. Equation (1) maybe written as

$$
\ln \frac{I_{\lambda}^{k i}}{A_{k i} g_{k}}=-\frac{E_{k}}{k_{B} T}+\ln \frac{C_{s} F}{Q}
$$

For the determination of the plasma temperature, a graph of $\ln \frac{I_{\lambda}^{k i}}{A_{k i} g_{k}}$ vs. $E_{k}$ was drawn, viz. a Boltzmann plot was constructed as illustrated in Figure 3.

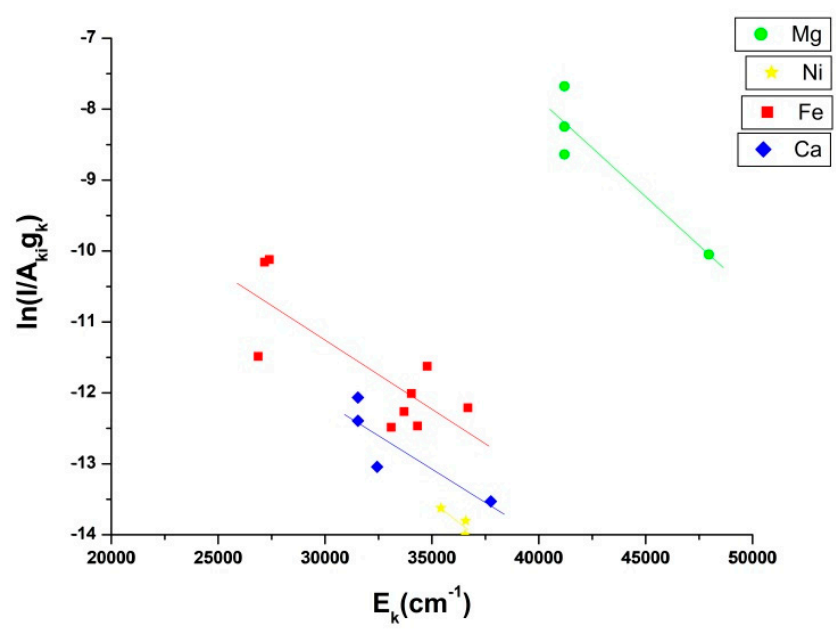

Figure 3. Boltzmann plot for different emission lines of elements for the Dergaon meteorite. 
According to the McWhirter criterion [30], plasma is inLTE if the value of electron density satisfies

$$
\mathrm{N}_{\mathrm{e}}\left(\mathrm{cm}^{-3}\right)>1.6 \times 10^{12} \times[\mathrm{T}(\mathrm{K})]^{1 / 2} \times[\Delta \mathrm{E}(\mathrm{eV})]^{3},
$$

where, $\mathrm{T}$ is the plasma temperature, $\mathrm{N}_{\mathrm{e}}$ is the electron density, and $\Delta \mathrm{E}$ is the energy difference between upper and lower level transitions. In the present work, $\mathrm{T}$ is calculated by the Boltzmann plot given in Figure 3. The plasma temperature inferred from the Boltzmannplot is $\mathrm{T}=12,064 \pm 912 \mathrm{~K}$. The average electron density of the laser-induced plasma is determined by measuring the full-width at half-maximum (FWHM), $\Delta \lambda_{1 / 2}$, of the Stark-broadened line of calcium $422.6 \mathrm{~nm}$, illustrated in Figure 4 , and using

$$
\Delta \lambda_{1 / 2}=2 \mathrm{w}\left[\mathrm{N}_{\mathrm{e}}\left(\mathrm{cm}^{-3}\right) / 10^{16}\right]
$$

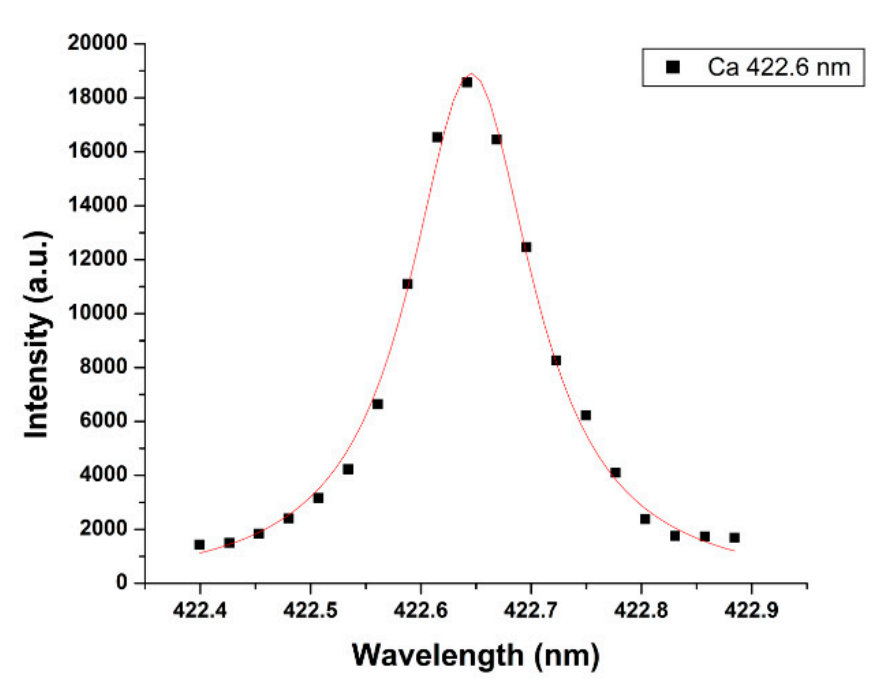

Figure 4. Measured and fitted Lorentzian of the Ca 422.6-nm line of the Dergaon meteorite.

Here, $w$ is the electron impact parameter. From Ref. [31]: $w=7.18 \times 10^{-3} \AA$. The FWHM is obtained from Figure 4, and the value of the electron density is $\mathrm{N}_{\mathrm{e}} \approx 1.54 \times 10^{18} \mathrm{~cm}^{-3}$. Therefore, the experimentally determined value of $\mathrm{N}_{\mathrm{e}}\left(\approx 10^{18} \mathrm{~cm}^{-3}\right)$ is larger than the limit set by the necessary McWhirter criterium thus, the laser-plasma is in LTE.

\subsection{Species Concentrations}

The concentrations, $\mathrm{C}_{\mathrm{s}}$, are determined in the context of CF-LIBS by using Equation(2) and the slope of the Boltzmann plot in Figure 3. The following method is applied:

(1) Find the area under of measured spectral lines of elements.

(2) Infer temperature by constructing a Boltzmann plot.

(3) Determine the intercept of the Boltzmann plot for each species.

(4) Calculate the partition function for each species.

(5) Evaluate the experimental efficiency factor, F, in Eq. (1), by normalizing the sum of the relative concentrations of all species in the sample, i.e., $\sum \mathrm{Cs}=1$

(6) Finally, conclude species concentrations.

Table 3 communicates that the concentrations of $\mathrm{Na}, \mathrm{Mg}, \mathrm{Al}, \mathrm{Si}, \mathrm{K}, \mathrm{Ca}, \mathrm{Ti}, \mathrm{Cr}, \mathrm{Mn}, \mathrm{Fe}, \mathrm{Co}$, and $\mathrm{Ni}$ determined in this work with CF-LIBS agree with the values reported using other methods, viz. INAA, AAS and ICP-AES, [2] and XRF [9] with deviations of the values within 10\%. The total percentage of the elements determined by Shukla et al. and Saika et al. [2,9] is $\approx 47 \%$ and $\approx 66 \%$, respectively. The reported element concentrations do not contain noble gases and light elements like $\mathrm{H}, \mathrm{N}$, and 
O. The LIBS spectra of the Dergaon meteorite recorded in ambient air show the presence of $H, N$, and $\mathrm{O}$ (see Figure 1d) unlike previous reports, although a minute atmospheric contribution cannot be ruled out. In the experiments, the interference of ambient air was suppressed by adjusting the distance between the lens and sample. The $\mathrm{H}, \mathrm{N}$, and $\mathrm{O}$ contents of the ambient air are 0.000055, 78.09, and $20.95 \%$, respectively. However, the present data show that the concentration of $\mathrm{O}$ is 40 times larger than that of $\mathrm{N}$ (see Table 3), indicating a small spectral interference from the ambient air in the spectra. Importantly, this work is the first report showing the presence of light elements in the Dergaon meteorite. The concentrations of the Dergaon meteorite obtained by CF-LIBS are summarized in Table 3 and are in close agreement with the earlier data acquired by AAS, ICP-AES, XRF, and INAA [2,9].

Table 3. Element concentrations in wt \% in the Dergaon meteorite from different measurements.

\begin{tabular}{|c|c|c|c|}
\hline Species & $\begin{array}{l}\text { INAA, AAS and } \\
\text { ICP-AES * (wt \%) }\end{array}$ & $X R F * *(w t \%)$ & CF-LIBS *** (wt \%) \\
\hline $\mathrm{H}$ & - & - & 0.27 \\
\hline $\mathrm{N}$ & - & - & 0.69 \\
\hline $\mathrm{O}$ & - & - & 33.50 \\
\hline $\mathrm{Na}$ & 0.7061 & 0.670 & 0.77 \\
\hline $\mathrm{Mg}$ & 13.6 & 14.26 & 13.44 \\
\hline $\mathrm{Al}$ & 1.09 & 1.20 & 1.70 \\
\hline $\mathrm{Si}$ & - & 17.30 & 17.42 \\
\hline $\mathrm{K}$ & 0.03 & 0.067 & 0.09 \\
\hline $\mathrm{Ca}$ & 1.08 & 1.19 & 1.77 \\
\hline $\mathrm{Ti}$ & - & 0.04 & 0.07 \\
\hline $\mathrm{Cr}$ & 0.3705 & 0.03 & 0.55 \\
\hline Mn & 0.2329 & - & 0.31 \\
\hline $\mathrm{Fe}$ & 27.3 & 27.73 & 27.90 \\
\hline $\mathrm{Co}$ & 0.08 & - & 0.07 \\
\hline $\mathrm{Ni}$ & 1.82 & 1.75 & 1.30 \\
\hline
\end{tabular}

\section{Materials and Methods}

The LIBS study was conducted on a sliced Dergaon fall meteorite sample, and five polished sections were used for petrographic study. Figure 5 illustrates the Dergaon sample. The LIBS spectra were obtained on a freshly cut even surface.

\section{Experimental Arrangement}

The experimental setup is similar to our recent study [22]. The $\mathrm{Nd}$ : YAG laser radiation (Continuum Surellite III-10) was adjusted to an energy/pulse of $15 \mathrm{~mJ}$ at $532 \mathrm{~nm}$. The pulse duration was $4 \mathrm{~ns}$. A repetition rate of $10 \mathrm{~Hz}$ was selected for the recording of LIBS spectra from the meteorite. Every spectrum presented in this study corresponds to the average of 50 laser shots taken at 10 different places on the sample. The laser beam was directly focused onto the flat, sliced surface of the Dergaon meteorite sample (see Figure 1) using a convergent lens with a focal length of $15 \mathrm{~cm}$ to produce laser-induced plasmaat the surface of the sample. Care was taken to avoid crater formation on the sample surface. The meteorite sample was placed on atranslation stage and was continuously moved to get a fresh surface for each laser shot and to cover a suitable area. The emitted light from the laser-induced plasma was collected and fed into the Mechelle spectrometer (ME5000, Andor Technology, South Windsor, CT, US) equipped with an intensified charge-coupled device (ICCD) detector (model iStar 334, Andor Technology, South Windsor, CT, USA). The experimental parameters, especially the gate delay and gate width, were optimized to obtain the best $\mathrm{S} / \mathrm{B}$ and $\mathrm{S} / \mathrm{N}$ ratios of $0.7 \mu \mathrm{s}$ and $4 \mu \mathrm{s}$, respectively. 

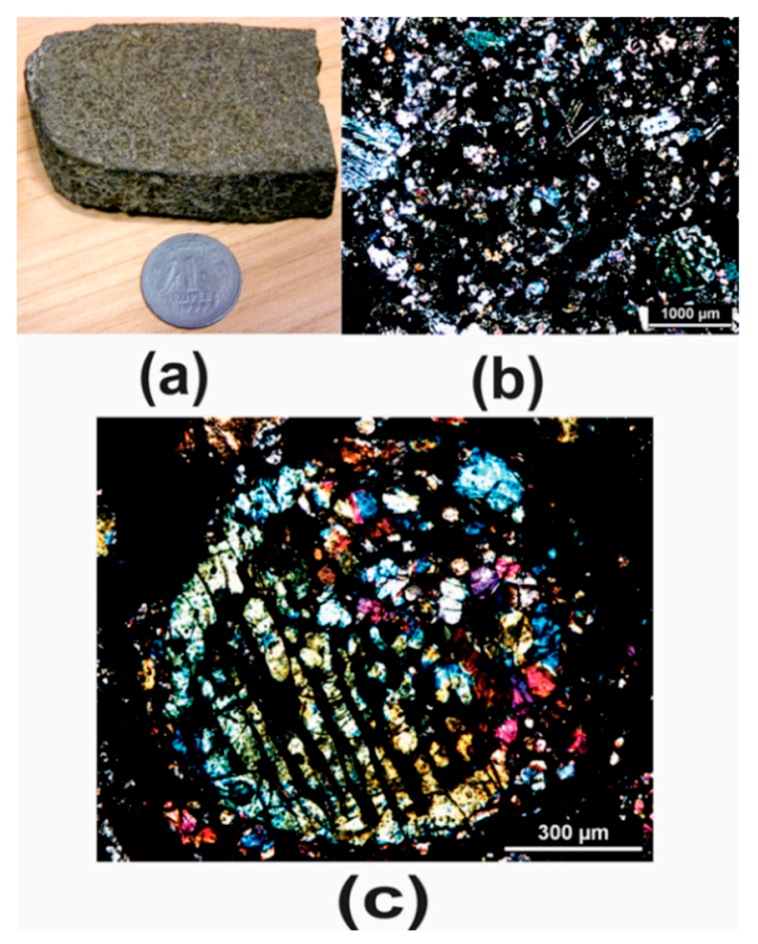

Figure 5. (a) Photograph of the Dergaon fall meteorite sample. (b) Photomicrograph of the Dergaon meteorite showing chondrules of various types and exhibiting porphyritic texture under crossed polarizers (c) A barred olivine chondrule from the Dergaon meteorite showing the olivine bars and a single rim in optical continuity. The glass phase is optically isotropic under crossed polarizers. Metallic phases are optically opaque.

\section{Conclusions}

The experimental investigation shows that laser-induced breakdown spectroscopy allows one to perform qualitative and quantitative elemental analysis of extraterrestrial materials with negligible sample loss. This is the first application of the calibration-free LIBS for a quantitative analysis of the Dergaon fall meteorite. The elemental concentration determination is similar to that obtained by conventional but time-consuming and expensive techniques, that cause significant sample destruction compared meager ablation loss observed during LIBS analysis. Identical to the previous study, the Dergaon meteorite shows depleted K concentration and Na concentrations much larger than $\mathrm{K}$ concentrations. It is an inherently $\mathrm{K}$-depleted $\mathrm{H}+$ chondrite [2] rather than the previously suggested impact-induced high-temperature alkali devolatilization process [3], since the laser-induced breakdown spectroscopy applied in the present study did not alter the inferred concentrations of alkali elements.The elevated $\mathrm{Mg}(13.44 \% \mathrm{wt}), \mathrm{Ni}(1.30 \% \mathrm{wt})$, and $\mathrm{Cr}(0.55 \% \mathrm{wt})$ contents and confirmed presence of $\operatorname{Ir}$ (the spectral line at $351.364 \mathrm{~nm}$ ) analogous to previous studies $[2,9,16]$, and the petrographic observations establish the Dergaon sample as a chondrite meteorite. In addition to the characteristic atomic lines of the elements that were recorded, the spectra also show molecular bands of molecules composed of elements that display relatively higher concentration.

Author Contributions: The samples, sample photographs, thin-sections are provided by B.B., A.C.M. and K.D. of Gauhati University, A.K.R. conducted the experimental investigations, and A.K.R., J.K.P., C.G.P., S.D., Awadhesh K.R. contributed to the writing of this article. All authors have read and agreed to the published version of the manuscript.

Funding: This research received no external funding.

Acknowledgments: One of the authors, Abhishek K. Rai, expresses thanks to the UGC (CRET) of India for financial assistance of his doctoral research at the University of Allahabad, UP, India. 
Conflicts of Interest: The authors declare no conflict of interest.

\section{References}

1. Bennett, M.E.; Mcsween, H.Y. Revised model calculations for the thermal histories of ordinary chondrite parent bodies. Meteorit. Planet. Sci. 1996, 31, 783-792. [CrossRef]

2. Shukla, P.N.; Shukla, A.D.; Rai, V.K.; Murty, S.V.S.; Bhandari, N.; Goswami, J.N.; Mazumdar, A.C.; Phukon, P.; Duorah, K.; Greenwood, R.E.; et al. The Dergaon (H5) Chondrite: Fall, Classification, Petrological and Chemical Characteristics, Cosmogenic Effects, and Noble Gas Records. Meteorit. Planet. Sci. 2005, 40, $627-637$. [CrossRef]

3. Ray, D.; Ghosh, S.; Goswami, T.K.; Jobin, M.J. Insights into chondrule formation process and shock-thermal history of the Dergaon chondrite (H4-5). Geosci. Front. 2017, 8, 413-423. [CrossRef]

4. Barua, A.G.; Boruah, B.R.; Bhattacharyya, S.; Baruah, G.D. Spectroscopic investigation of the Dergaon meteorite with reference to $10 \mathrm{~mm}$ and $20 \mathrm{~mm}$ bands. Pramana 2003, 60, 47-52. [CrossRef]

5. Bhattacharyya, S.; Barua, A.G.; Konwar, R.; Changmai, R.; Baruah, G.D. Nature of the Emission Band of Dergaon Meteorite in the Region 5700-6700 Å. Pramana 2004, 62, 1299-1301. [CrossRef]

6. Saikia, B.J.; Parthasarathy, G.; Sarmah, N.C.; Baruah, G.D. Organic compounds in H5 meteorite: Spectroscopic investigation of Dergaon H5 chondrite. Geochim. Cosmochim. Acta 2009, 71, 867-882.

7. Saikia, B.J.; Parthasarathy, G. Spectroscopy of Dergaon meteorite. Geochim. Cosmochim. Acta 2008, 72, 818-828.

8. Saikia, B.J.; Parthasarathy, G.; Sarmah, N.C. Fourier transform infrared spectroscopic characterization of Dergaon H5 chondrite: Evidence of aliphatic organic compound. Nat. Sci. 2009, 7, 45-51.

9. Saikia, B.J.; Parthasarathy, G.; Sarmah, N.C. Spectroscopic characterization of olivine $[(\mathrm{Fe}, \mathrm{Mg}) 2 \mathrm{SiO} 4]$ in Mahadevpur H4/5 ordinary chondrite. J. Am. Sci. 2009, 5, 71-78.

10. Saikia, B.J.; Parthasarathy, G.; Borah, R.R. Nanodiamonds and silicate minerals in ordinary chondrites as determined by micro-Raman spectroscopy Meteorit. Planet Sci. 2017, 52, 1146-1154. [CrossRef]

11. Ciucci, A.; Corsi, M.; Palleschi, V.; Rastelli, S.; Salvetti, A.; Tognoni, E. New Procedure for Quantitative Elemental Analysis by Laser-Induced Plasma Spectroscopy. Appl. Spectrosc. 1999, 53, 960-964. [CrossRef]

12. De Giacomo, A.; Dell'Aglio, M.; De Pascale, O.; Longo, S.; Capitelli, M. Laser induced breakdown spectroscopy on meteorites. Spectrochim. Acta Part B: At. Spectrosc. 2007, 62, 1606-1611. [CrossRef]

13. Dell'Aglio, M.; De Giacomo, A.; Gaudiuso, R.; Pascale, O.D.; Senesi, G.S.; Longo, S. Laser Induced Breakdown Spectroscopy applications to meteorites: Chemical analysis and composition profiles. Geochim. Cosmochim. Acta 2010, 74, 7329-7339. [CrossRef]

14. Cousin, A.; Sautter, V.; Fabre, C.; Maurice, S.; Wiens, R.C. Textural and modal analyses of picritic basalts with ChemCam laser-induced breakdown spectroscopy. J. Geophys. Res. 2012, 117, E10002. [CrossRef]

15. Horňáčková, M.; Plavčan, J.; Rakovský, J.; Porubčan, V.; Ozdín, D.; Veis, P. Calibration-free laser induced breakdown spectroscopy as an alternative method for found meteorite fragments analysis. Eur. Phys. J. 2014, 66, 10702.

16. Senesi, G.S.; Manzari, P.; Tempesta, G.; Agrosì, G.; Touchnt, A.A.; Ibhi, A.; De Pascale, O. Handheld Laser Induced Breakdown Spectroscopy Instrumentation Applied to the Rapid Discrimination between Iron Meteorites and Meteor-Wrongs. Geostand. Geoanalytical. Res. 2018, 42, 607-614. [CrossRef]

17. Pandhija, S.; Rai, N.K.; Rai, A.K.; Thakur, S.N. Contaminant concentration in environmental samples using LIBS and CF-LIBS. Appl. Phys. B 2009, 98, 231-241. [CrossRef]

18. Koeberl, C.; Shirey, S.B. Detection of a Meteoritic Component in Ivory Coast Tektites with Rhenium-Osmium Isotopes. Science 1993, 261, 595-598. [CrossRef]

19. Tagle, R.; Hecht, L. Geochemical identification of projectiles in impact rocks. Meteorit. Planet. Sci. 2006, 41, 1721-1735. [CrossRef]

20. Misra, S.; Newsom, H.E.; Prasad, M.S.; Geissman, J.W.; Dube, A.; Sengupta, D. Geochemical identification of impactor for Lonar crater, India. Meteorit. Planet. Sci. 2009, 44, 1001-1018. [CrossRef]

21. Pati, J.K.; Qu, W.J.; Koeberl, C.; Reimold, W.U.; Chakarvorty, M.; Schmitt, R.T. Geochemical evidence of an extraterrestrial component in impact melt breccia from the PaleoproterozoicDhala impact structure. India Meteorit. Planet. Sci. 2017, 52, 722-736. [CrossRef]

22. Rai, A.K.; Pati, J.K.; Kumar, R. Spectro-chemical study of moldavites from Ries impact structure (Germany) using LIBS. Opt. Laser Technol. 2019, 114, 146-157. [CrossRef] 
23. National Institute of Standards and Technology (NIST) Electronic Database. Available online: http: //physics.nist.gov/PhysRefData/ASD/linesform.html (accessed on 26 October 2019).

24. Nachon, M.; Clegg, S.M.; Mangold, N.; Schröder, S.; Kah, L.C.; Dromart, G.; Ollila, A.; Johnson, J.R.; Oehler, D.Z.; Bridges, J.C.; et al. Calcium sulfate veins characterized by ChemCam/Curiosity at Gale crater, Mars. J. Geophys. Res. Planets 2014, 119, 1991-2016. [CrossRef]

25. Rai, A.K.; Pati, J.K.; Parigger, C.G.; Rai, A.K. Plasma Spectroscopy of Various Types of Gypsum: An Ideal Terrestrial Analogue. Atoms 2019, 7, 72. [CrossRef]

26. Cheung, A.-C.; Lyyra, A.; Merer, A.; Taylor, A. Laser spectroscopy of FeO: Rotational analysis of some subbands of the orange system. J. Mol. Spectrosc. 1983, 102, 224-257. [CrossRef]

27. Cremers, D.A.; Radziemski, L.J. Handbook of Laser-Induced Breakdown Spectroscopy; John Wiley: Chichester, UK, 2013.

28. Kumar, R.; Rai, A.K.; Alamelu, D.; Aggarwal, S.K. Monitoring of toxic elements present in sludge of industrial waste using CF-LIBS. Environ. Monit. Assess. 2012, 185, 171-180. [CrossRef] [PubMed]

29. Thakur, S.N. Atomic emission spectroscopy. In Laser Induced Breakdown Spectroscopy; Singh, J.P., Thakur, S.N., Eds.; Elsevier: Amsterdam, NL, 2007; pp. 23-48.

30. Singh Maurya, G.; Jyotsana, A.; Kumar, R.; Kumar, A.; Rai, A.K. Analysis of Deposited impurity material on the surface of optical window of the Tokamak using LIBS. Phys. Scr. 2014, 89, 075601. [CrossRef]

31. Griem, H.R. Plasma Spectroscopy; McGraw-Hill: New York, NY, USA, 1964.

Sample Availability: Samples of the compounds are available from the authors.

(C) 2020 by the authors. Licensee MDPI, Basel, Switzerland. This article is an open access article distributed under the terms and conditions of the Creative Commons Attribution (CC BY) license (http://creativecommons.org/licenses/by/4.0/). 